\title{
Retraction Note to: Transient analysis of an M/M/1 queue with variant impatient behavior and working vacations
}

\author{
R. Sudhesh ${ }^{1} \cdot$ A. Azhagappan ${ }^{2}$
}

Accepted: 11 October 2019 / Published online: 30 October 2019

(c) Operational Research Society of India 2019

\section{Retraction to: OPSEARCH (2018) 55:787-806 https://doi.org/10.1007/s12597-018-0339-8}

The editor has retracted this article [1] because it has significant overlap with a work published by Sudhesh and Azhagappan [2] and is therefore redundant. The authors do not agree to this retraction.

\section{References}

1. Sudhesh, R., Azhagappan, A.: Transient analysis of an $\mathrm{M} / \mathrm{M} / 1$ queue with variant impatient behavior and working vacations. OPSEARCH 55, 787 (2018). https://doi.org/10.1007/s12597-018-0339-8

2. Sudhesh, R., Azhagappan, A.: Transient analysis of $\mathrm{M} / \mathrm{M} / 1$ queue with server vacation customers impatient and a waiting server timer. Asian J. Res. Soc. Sci. Humanit. 6(9), 1096-1104 (2016). https ://doi.org/10.5958/2249-7315.2016.00857.1

Publisher's Note Springer Nature remains neutral with regard to jurisdictional claims in published maps and institutional affiliations.

The original article can be found online at https://doi.org/10.1007/s12597-018-0339-8.

R. Sudhesh

sudhesh@aucev.edu.in

A. Azhagappan

azhagappanmaths@gmail.com

1 Department of Mathematics, Bharathidasan Institute of Technology (BIT) Campus, Anna University, Tiruchirappalli, Tamilnadu 620 024, India

2 Department of Mathematics, St. Anne's College of Engineering and Technology, Anna University, Panruti, Cuddalore District, Tamilnadu 607 110, India 